\title{
Supplemental Materials
}

for

\section{Carbon Dioxide and Methane Measurements from the Los Angeles Megacity Carbon Project: 1. Calibration, Urban Enhancements, and Uncertainty Estimates}

In this document we show: (1) Estimates of epsilon (the slope component of the extrapolation uncertainty) for $\mathrm{CO}_{2}$ and $\mathrm{CH}_{4}$ based on laboratory measurements using CRDS analyzer units similar to those deployed in the field; (2) Uncertainty due to permeability of the Nafion drier determined from laboratory experiments; (3) Results from an Allan deviation analysis conducted using daily calibration runs from the LJO (La Jolla) analyzer during January 2016; (4) Example plots showing the $\mathrm{CO}_{2}$ and $\mathrm{CH}_{4}$ calibration baseline uncertainty using three possible time series of Picarro sensitivity for the standard tank measurements from the LJO site during January 2016.

\section{S1 Uncertainty due to Nafion drier permeability}

The laboratory experiments described here were performed at the Scripps Institution of Oceanography to estimate the uncertainty in the water vapor correction due to bias caused by the permeation of $\mathrm{CO}_{2}$ and $\mathrm{CH}_{4}$ across the membrane of the Nafion drier. We measured two dry standard tanks for 1200 seconds each, alternating one directly after the other. The measurement system setup was identical to those used at our field sites, with a Nafion dryer located upstream of the instrument. The water vapor concentrations at the start of the measurements were $0.095 \%$, reflective of the Nafion dryer conditions during the ambient air measurements just prior to this experiment. As the measurements continued, the Nafion dryer gradually dried out, which reduced the permeation of $\mathrm{CO}_{2}$ and $\mathrm{CH}_{4}$ across the membrane. This effect leads to a small increase in the $\mathrm{CO}_{2}$ and $\mathrm{CH}_{4}$ levels measured on the Picarro analyzer (Figure S3). In this experiment we assume that other factors such as instrument drift are negligible over the duration of this experiment (approximately 16 hours).

The uncertainty due to the Nafion permeation effect is derived from the slope of measured $\mathrm{CO}_{2}, \mathrm{CH}_{4}$ concentrations against water vapor concentrations during our experiment, as shown in Figure $\mathrm{S}$. $\mathrm{CO}_{2}$ concentrations are found to decrease at a ratio of $-1.15 \mathrm{ppm}$ per $1 \%$ change in water vapor concentration in the range of 0 to roughly $0.095 \%$, while $\mathrm{CH}_{4}$ concentrations are found to be small at a ratio of 0.029 ppb per $1 \%$ water vapor concentration change within a range of 0.03 to roughly $0.095 \%$. As the water vapor concentrations in our field measurements lie within a range of $0.01 \pm 0.001 \%$, we estimate the potential bias introduced by the $0.001 \%$ range in water vapor concentrations to be $-0.0115 \mathrm{ppm}$ for $\mathrm{CO}_{2}$ and $0.000029 \mathrm{ppb}$ for $\mathrm{CH}_{4}$.

Note that while the permeability of $\mathrm{CH}_{4}$ through the Nafion membrane is shown to change dramatically in water vapor concentrations lower than $0.03 \%$, this effect can be effectively ignored for our purposes considering the 
range of water vapor concentrations measured at our sites.

Also, since the relationship between permeation through the Nafion membrane and water vapor concentration has been established, it is also possible to correct for this bias and report an uncertainty on the confidence of our understanding of this relationship. This correction may potentially be added in the future, which would further reduce the uncertainties due to this effect. 

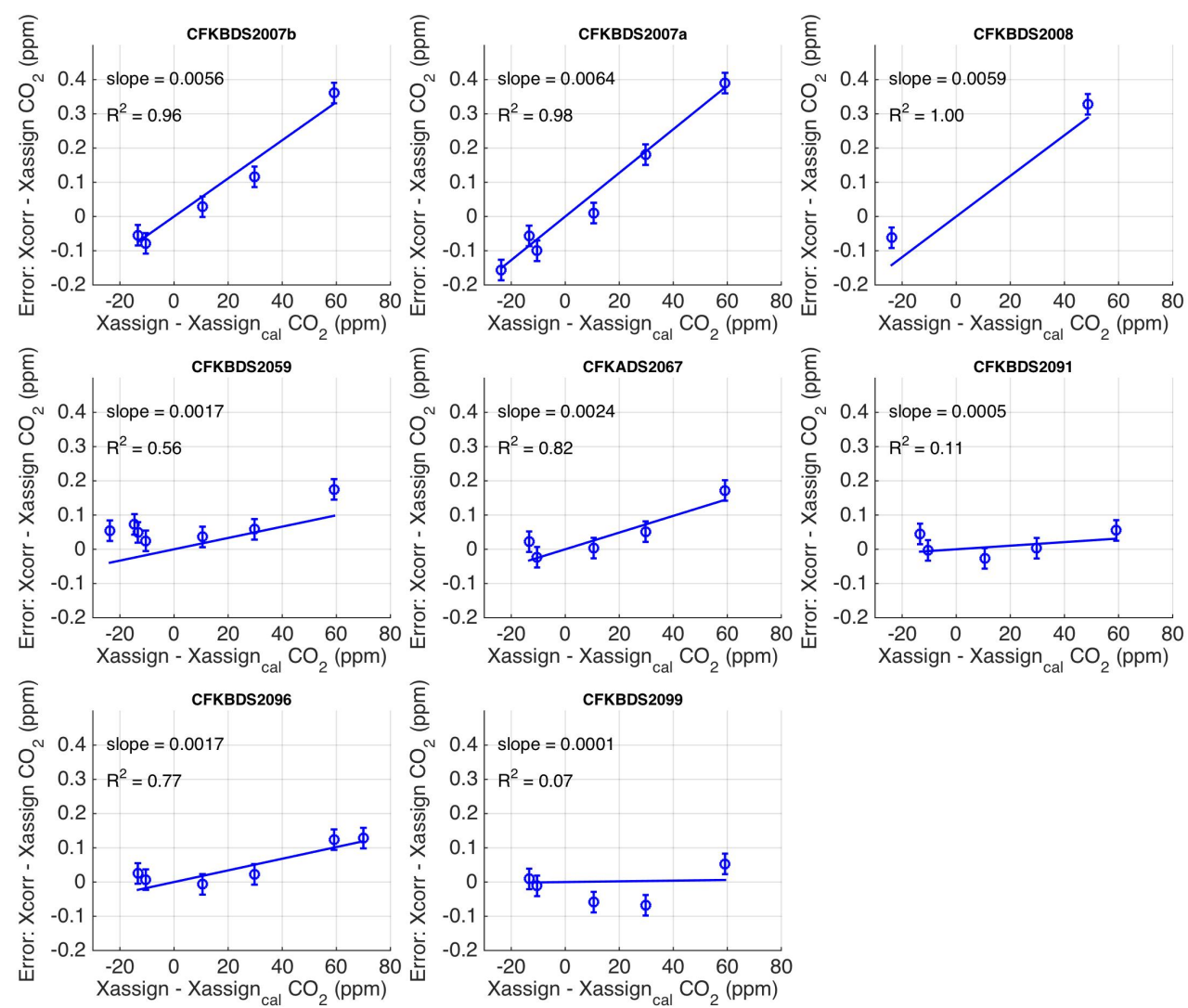

Figure S1. Estimates for epsilon $(\varepsilon)$, the slope component of the extrapolation uncertainty $\left(u_{e x}\right)$ for $\mathrm{CO}_{2}$ based on measurements from seven Picarro CRDS analyzer units. All calibrations were performed on the same suite of tanks at the NOAA/ESRL calibration laboratory. Xassign $n_{\text {cal }}$ is the assigned value of the calibration standard, in this case the tank with $\mathrm{CO}_{2}$ value closest to $400 \mathrm{ppm}$. This tank was used to correct the raw measurements of other standard gases using Eq. 2 in the main text. The slope of the residual (Xcorr - Xassign) is plotted as a function of the concentration difference between each standard tank and the assigned calibration tank $\left(\right.$ Xassign $_{\text {span }}-X_{\text {Xassign }}$ cal $)$, and is a measure of $\varepsilon$. All tanks were calibrated on the WMO/NOAA scales at the NOAA/ESRL laboratory. The same suite of standard tanks was also run on each analyzer prior to deployment for various field campaigns (with the exception of CFKBDS2008). All Picarro analyzers shown here are similar to those deployed in the LA network. All regressions are forced through zero. Error bars show the scale reproducibility $(1 \sigma)$ for the tank values reported by NOAA/ESRL ( $0.03 \mathrm{ppm} \mathrm{CO}_{2}$; Andrews et al., 2014 and B. Hall, personal communication). Figures for CFKBDS2007a and CFKBDS2007b indicate two different calibrations of the same analyzer. 

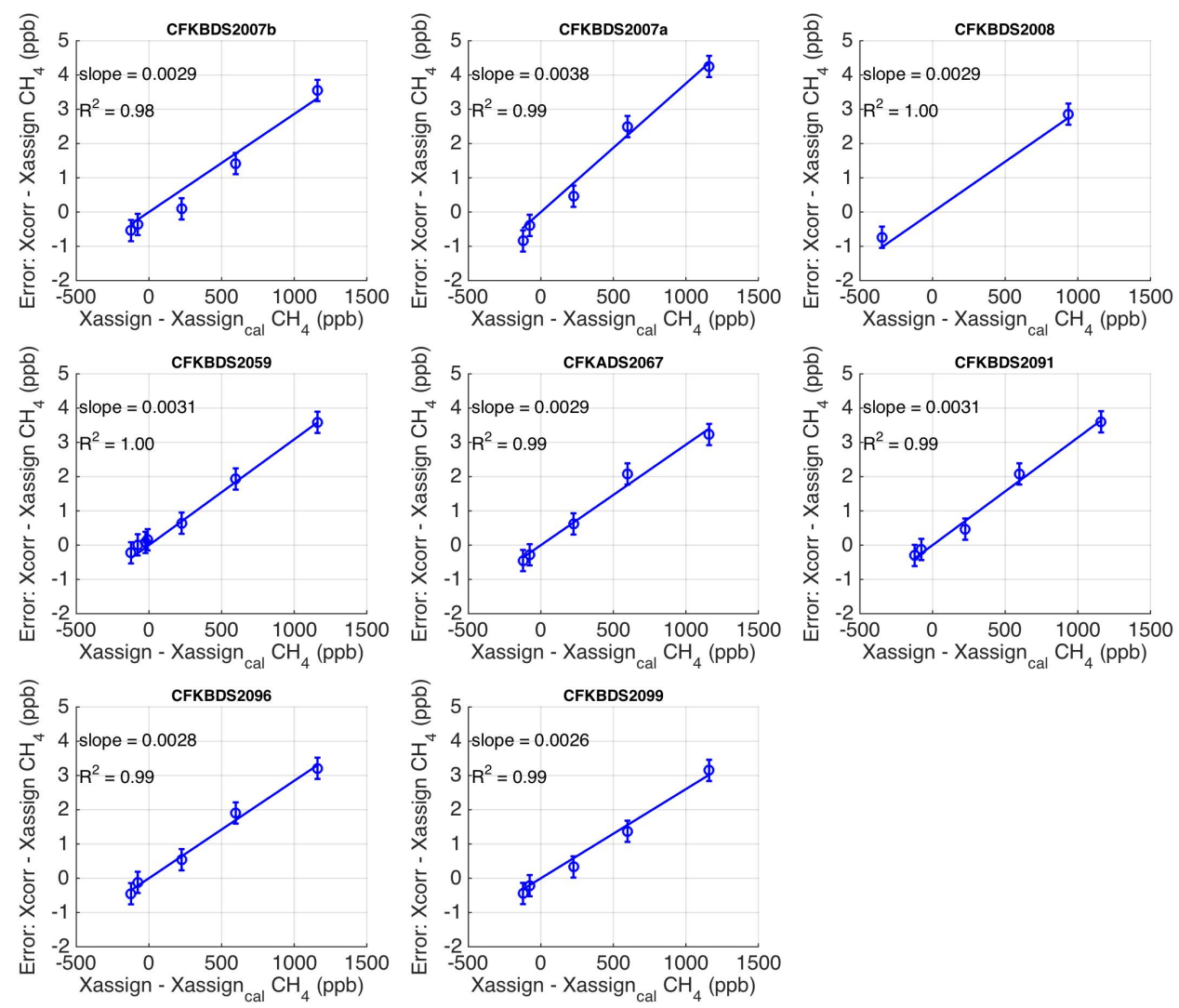

Figure S2. Estimates of epsilon $(\varepsilon)$, the slope component of the extrapolation uncertainty $\left(u_{e x}\right)$ for $\mathrm{CH}_{4}$ using the same suite of tanks as in Figure S2. All regressions are forced through zero. Error bars show the scale reproducibility $(1 \sigma)$ for tank values reported by NOAA/ESRL (0.31 ppb; $\mathrm{CH}_{4}$ Andrews et al., 2014). 

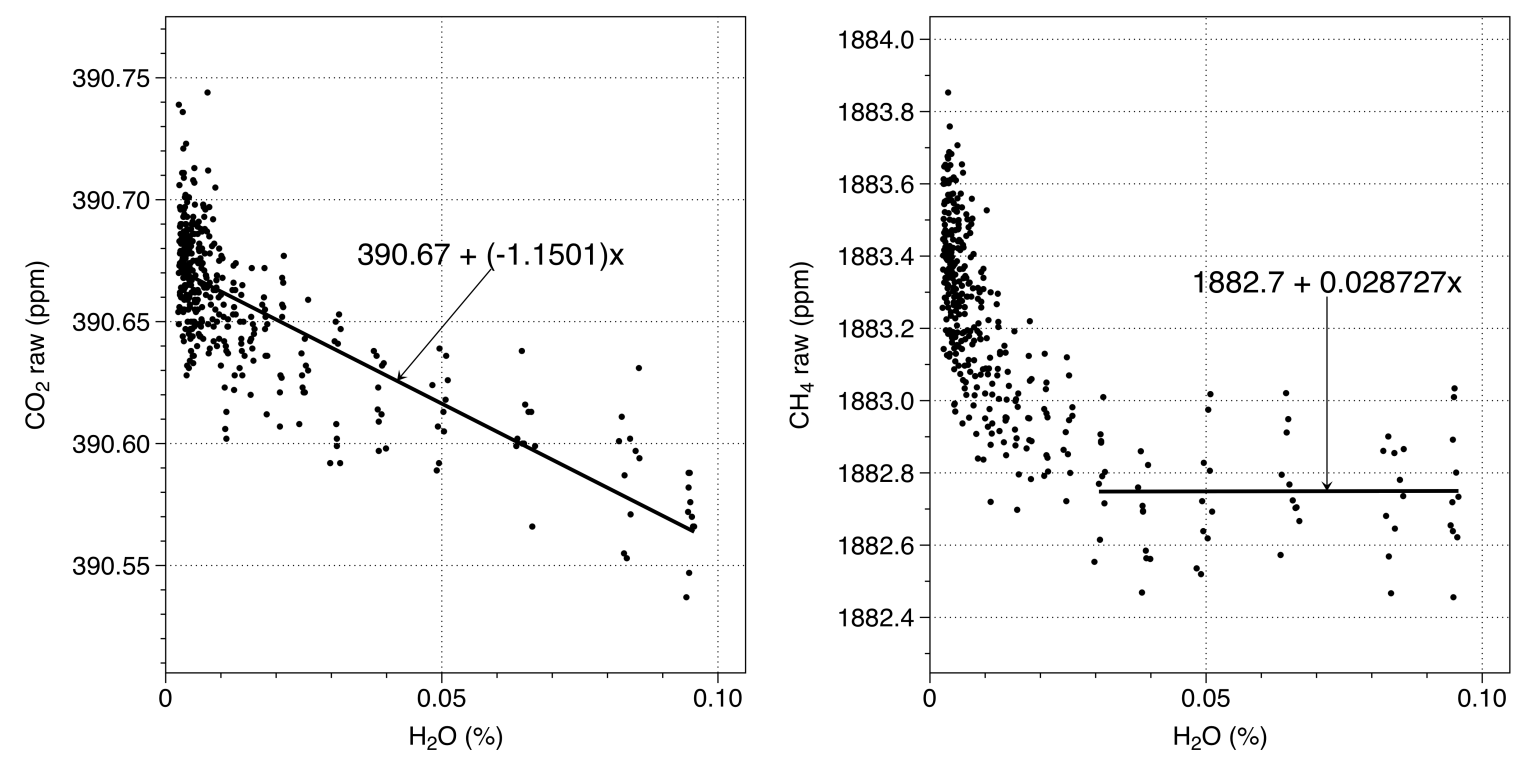

Figure S3. Results of Nafion permeation experiment. A slight increase in the measured $\mathrm{CO}_{2}$ and $\mathrm{CH}_{4}$ levels (shown here as uncalibrated CRDS readings) was found as the Nafion membrane dried out, leading to less permeation across the membrane throughout the experiment. We assume that these changes in the measured concentrations are not due to any other factors such as instrument drift. For simplification, only one of the two tanks measured during the experiment is shown. For $\mathrm{CO}_{2}$, the relationship between measured concentrations and water vapor concentration is derived for the complete water vapor concentration range. For $\mathrm{CH}_{4}$ we only consider the range of 0.03 to $0.095 \%$ $\mathrm{H}_{2} \mathrm{O}$ since the permeation effect is different at lower water vapor concentrations, and the water vapor concentration for the field measurements in our network are within the $0.01 \pm 0.001 \%$ range. 

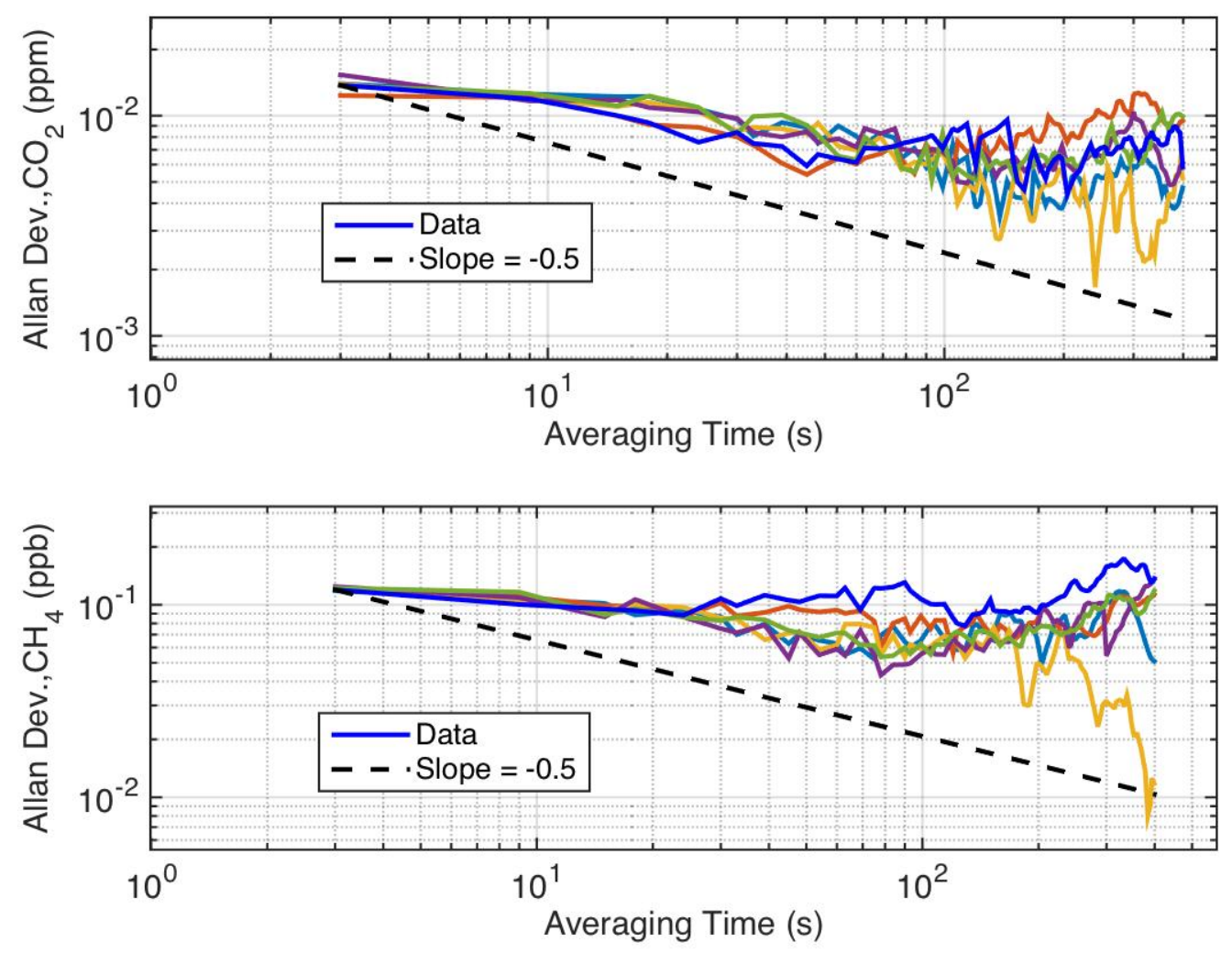

Figure S4. Allan deviation analysis from a subset of the daily calibration runs collected on the LJO analyzer during January 2016 (every $5^{\text {th }}$ run is plotted for clarity). The results show that the characteristics of the noise in the analyzer vary with time. In general, the results for the calibrations are not all the same and do not fit a white-noise profile (indicated by the dashed line with slope of $-1 / 2$ ), indicating correlation in the noise at various longer time scales. 

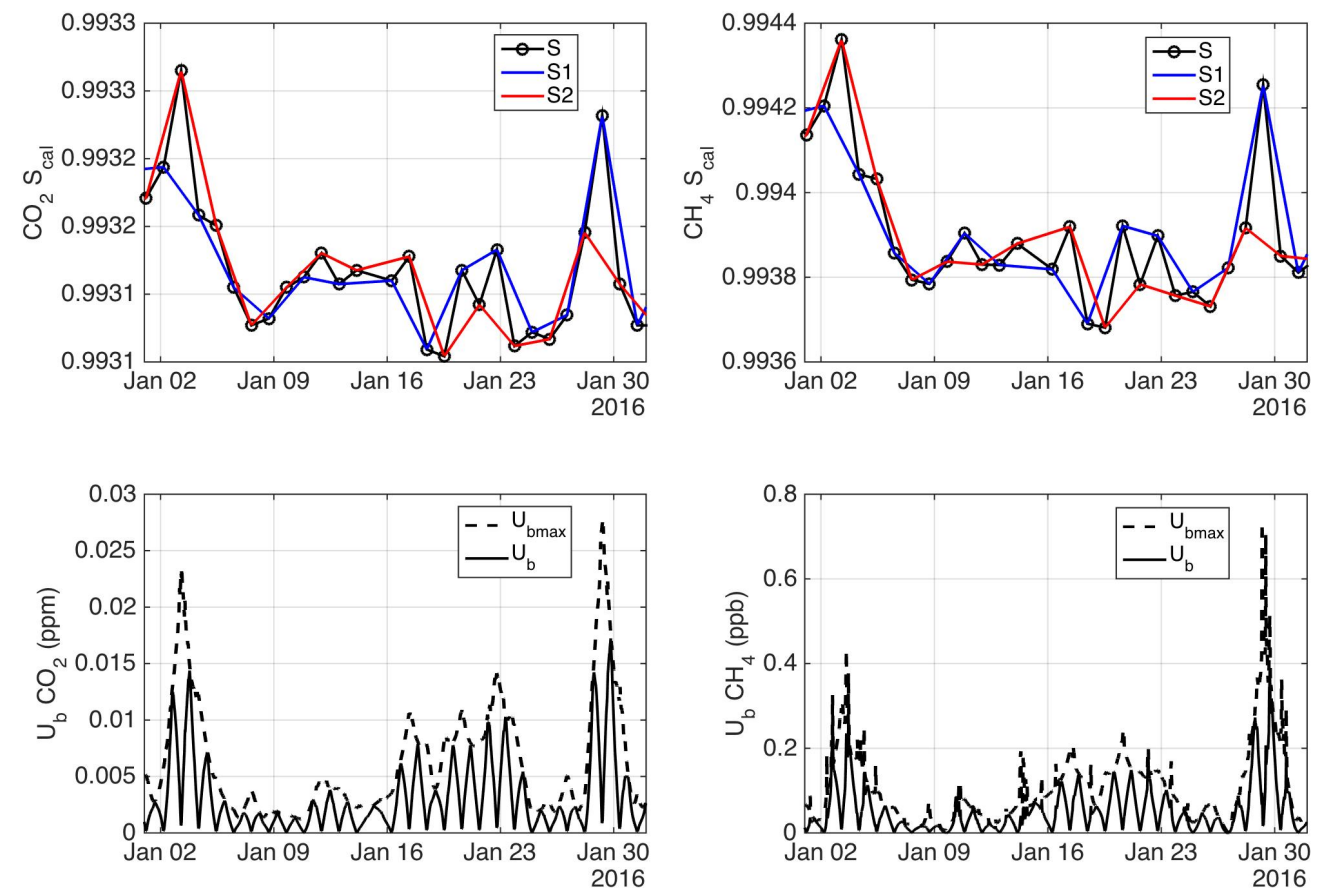

Figure S5. Example showing three possible time series of Picarro sensitivity for the standard tank measurement (upper panels) and the impact on estimates of calibration baseline uncertainty (lower panels). Results are shown for LJO data collected during January 2016. Upper panels: $\mathrm{S}$ is the sensitivity of the standard at the times when the reference tank was sampled (black points), which is calculated as the ratio of the measured analyzer mole fraction for the reference gas and the tank's assigned value (see text). The sensitivity of the standard is linearly interpolated in time, as shown by the black lines for $\mathrm{CO}_{2}$ (left) and $\mathrm{CH}_{4}$ (right). S1 (blue lines) and S2 (red lines) are two alternate realizations of the analyzer sensitivity based on different interpolation methods (e.g. interpolating at points halfway between the sequential standard tank measurements, leaving out every other point). Lower panels:

Calibration baseline uncertainty $\left(u_{b}\right.$ and $u_{b \max }$ ) calculated for $\mathrm{CO}_{2}$ (left) and $\mathrm{CH}_{4}$ (right). $u_{b}$ reduces to zero at the times when the calibration gas was run because the tank value is measured at that time. 

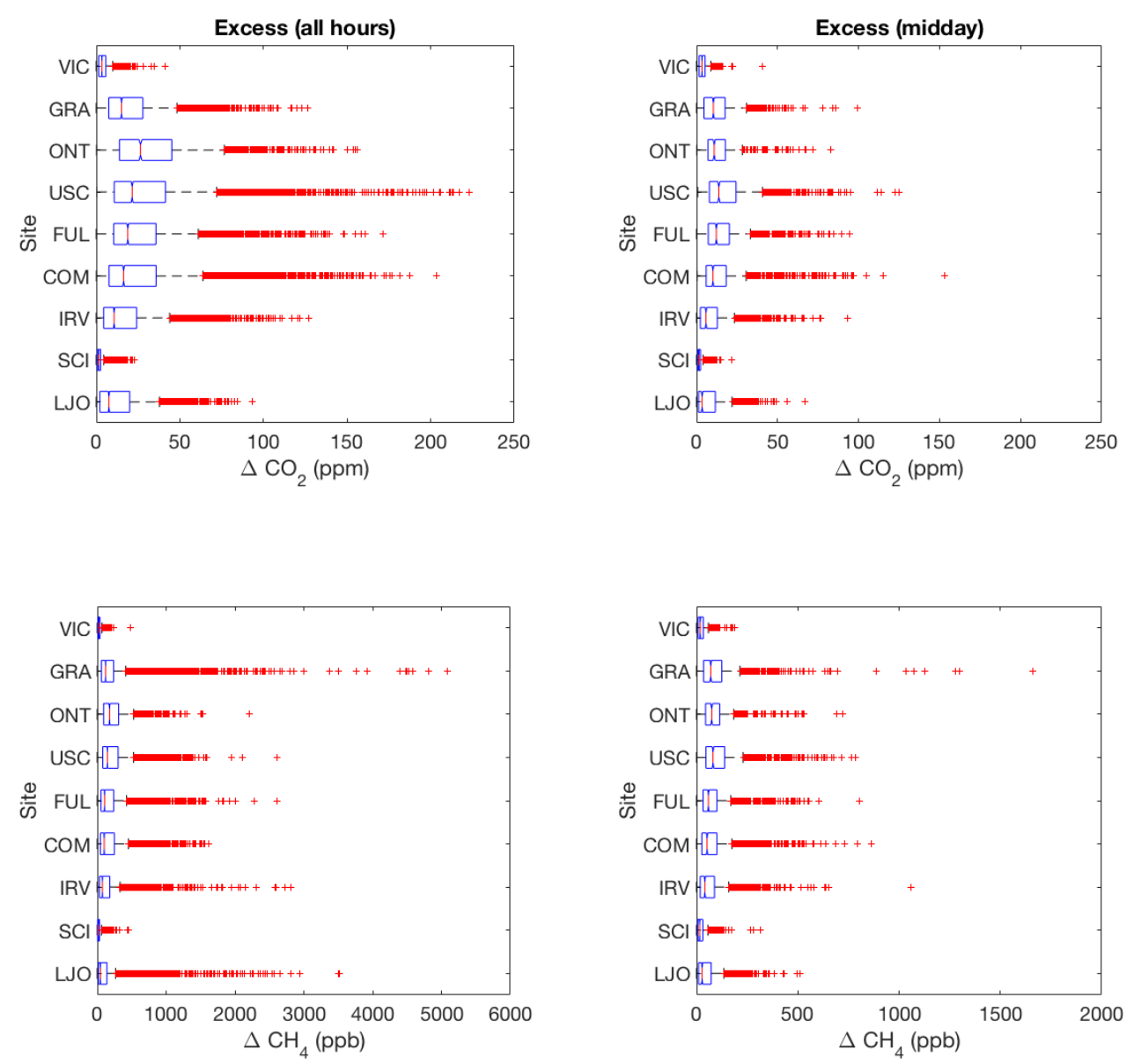

Figure S6: Boxplot of enhancements $\left(\Delta \mathrm{CO}_{2}\right.$ and $\left.\Delta \mathrm{CH}_{4}\right)$ in the LA megacity during (same as Figure 6 in the main text, but with outliers shown). Results for $\Delta \mathrm{CO}_{2}$ (upper panels) and $\Delta \mathrm{CH}_{4}$ (lower panels) are shown for all hours (left panels) and midday hours (12-16:00 LT, right panels). Boxes outline the $25^{\text {th }}$ and $75^{\text {th }}$ percentiles of the sample data, respectively and red horizontal lines show the median values at each site. The sites are arranged by latitude from north to south (top to bottom): Victorville (VIC), Granada Hills (GRA), Ontario (ONT), University of Southern California (USC), Fullerton (FUL), Compton COM), Irvine (IRV), San Clemente Island (SCI) and La Jolla (LJO). The maximum whisker length is specified as 1.0 times the interquartile range (i.e. $\left[\mathrm{q}_{3}+\mathrm{w}^{*}\left(\mathrm{q}_{3}-\mathrm{q}_{1}\right)\right]$ and $\left[\mathrm{q}_{1}-\right.$ $\left.\mathrm{w}^{*}\left(\mathrm{q}_{3}-\mathrm{q}_{1}\right)\right]$, where $\mathrm{q}_{1}$ and $\mathrm{q}_{3}$ are the $25^{\text {th }}$ and $75^{\text {th }}$ percentiles and $\left.\mathrm{w}=1.0\right)$. Outliers $(+)$ are shown for enhancements that are greater (or less than) the maximum whisker length. Note, results for the ONT site only include observations for Sept -Dec 2015, while all other results are annual averages. 


\section{References}

Andrews, A. E., Kofler, J. D., Trudeau, M. E., Williams, J. C., Neff, D. H., Masarie, K. A., Chao, D. Y., Kitzis, D. R., Novelli, P. C., Zhao, C. L., Dlugokencky, E. J., Lang, P. M., Crotwell, M. J., Fischer, M. L., Parker, M. J., Lee, J. T., Baumann, D. D., Desai, A. R., Stanier, C. O., De Wekker, S. F. J., Wolfe, D. E., Munger, J. W. and Tans, P. P.: $\mathrm{CO}_{2}, \mathrm{CO}$, and $\mathrm{CH}_{4}$ measurements from tall towers in the NOAA Earth System Research Laboratory's Global Greenhouse Gas Reference Network: instrumentation, uncertainty analysis, and recommendations for future highaccuracy greenhouse gas monitoring efforts, Atmos. Meas. Tech., 7(2), 647-687, doi:10.5194/amt-7-647-2014, 2014. 